\title{
EndNote training for academic staff and students: the experience of the Manchester Metropolitan University Library
}

Mary Harrison, Stephanie Summerton and Karen Peters

Mary Harrison is the Research Support Librarian, Manchester Metropolitan University Library, Oxford Road, Manchester, United Kingdom, M15 6BH Stephanie Summerton was formerly Assistant Librarian, Hollings Faculty, Manchester Metropolitan University Library, Oxford Road, Manchester, United Kingdom, M15 6BH

Karen Peters is Senior Assistant Librarian, INFOSKILLS, Manchester Metropolitan University Library, Oxford Road, Manchester, United Kingdom, M15 6BH

\section{ABSTRACT}

This article describes how the Manchester Metropolitan University Library delivers EndNote training to its academic staff and students through hands-on workshops and online tutorials. As the demand is user-led and the response extremely positive, the Library considers the provision of EndNote training as analogous to a "Trojan horse" which allows the Library welcomed and unchallenged into the camp of the user. The Library has used the opportunity strategically and, consequently, has benefitted in a number of ways, including improved communication with academic staff and increased awareness of library resources on the part of users. A short literature review is provided.

\section{INTRODUCTION}

The Manchester Metropolitan University (MMU) is a large higher education institution with five campuses in the Manchester city centre and two at some distance away in Cheshire. In academic year 2003-2004, the number of full-time equivalent students was just over 28,000 and the number of teaching staff was 1,050. Approximately $66 \%$ of the students were studying at first degree level. Although the management of the library service is centralised, there is a site library and a team of library staff at each campus, managed by a Library Services Manager. 
Following recommendations from academic staff, MMU purchased EndNote through a national consortial deal in mid-2001. To promote the availability of the software but with no plans of providing training, the Library's Research Support Librarian launched a series of presentations to academic staff. The response was enthusiastic as the academics immediately recognised that EndNote offered an effective and simple means of managing their references, and would allow them to dedicate their time to researching and writing rather than sorting out complex bibliographic formats and arcane punctuation. Even though they acknowledged that EndNote was relatively straightforward to use, they felt that in order to learn to use the software proficiently and quickly, formal training was required. They confessed that, without the commitment that attending a course required, they would never find the time to learn to use EndNote on their own.

Seeing this as an opportunity to meet the needs of a key group of its users, the Library responded by developing an EndNote training programme, which is now in its third year of operation. MMU's experience has been very positive and shows that the provision of such training not only supports the academic work of the University's staff and students but also accrues a number of benefits to the Library itself.

\section{LITERATURE REVIEW}

Although there is a small body of literature relating to the provision of citation manager training for library users, few authors have examined the impact this training has on libraries themselves. In his survey of the levels of bibliographic software training in Australian academic libraries, East (2001) highlights the growing trend for libraries to offer hands-on training courses for postgraduate students and academics in the use of EndNote and similar citation management packages. He suggests that this broadening role for librarians as software trainers is a natural progression from their traditional user education activities, such as providing instruction in electronic database searching. In fact, most studies 
discussing the methods employed in the delivery of citation manager training show that the training format is usually adapted from approaches used in information skills training -- a workshop involving presentations, demonstrations of the resource and hands-on practice in guided exercises (Koskinen, 2001; Owen, 1997; and Robinson Levy and Hinegardner, 1992). In looking at the delivery of EndNote training at Lehigh University library in the United States, Siegler and Simboli (2002) point out that these sessions can have positive rewards for the library, such as the enhanced visibility of library services and the facilitation of the use of library resources. Likewise, according to East (2001, p. 65), many libraries find that EndNote training can "raise the profile [of the library] in the academic community".

However, the provision of EndNote training is not without its drawbacks. The literature shows that significant staff time and resources are invariably needed to teach EndNote workshops as small workshop sizes and long sessions are typically required, and trainers must have good working knowledge of the software (East, 2001; Robinson Levy and Hinegardner, 1997; Siegler and Simboli, 2002). Within these limitations it is difficult for libraries to provide enough workshops to meet the demands of the user community or offer more flexible and advanced learning options. East's study reveals that, due to these constraints, many libraries are reluctant to wholeheartedly embrace citation manager training. At MMU, innovative approaches to delivering EndNote training have been developed in order to address these limitations, and to take advantage of the positive opportunities that the provision of EndNote training can offer a library.

\section{DEVELOPMENT OF ENDNOTE TRAINING WORKSHOPS}

The initial development of EndNote training became the responsibility of the Research Support Librarian, who adapted the format of workshops run by Adept Scientific (suppliers of EndNote in the United Kingdom). The first half of the threehour workshop teaches the basics of building an EndNote library, both manually and automatically through the use of connection files, import filters and direct 
export. The second half introduces Cite While You Write, which uses EndNote records to create citations and lists of references within Word documents. The workshops, held in the University's computer suites, consist of a PowerPoint presentation plus live demonstrations of the main EndNote functions. As each function is explained, participants are asked to complete a hands-on exercise to provide practical experience of using EndNote. Each participant is provided with a workbook adapted from the PowerPoint presentation, a general information leaflet on EndNote, a help sheet on the MMU library catalogue import filter, and a feedback form.

When running workshops, the Research Support Librarian had the support of the Serials Librarian who wanted an opportunity to gain teaching experience. Her assistance proved invaluable, particularly during the hands-on part of the workshop when participants often required individual support simultaneously. The use of two trainers also proved popular with workshop participants who appreciated the change of pace and voice. In academic year 2003-2004, three workshops were run for a combination of academics and postgraduate students. As support for the hands-on component of the workshop proved very demanding, the number of participants was deliberately restricted to twelve per workshop.

\section{TAKING A TEAM APPROACH: THE ENDNOTE CHAMPIONS}

The workshops were very well-received but, in order to meet escalating demand, it was evident that additional trainers were required. Library Services Managers, aware of the positive response from academic staff, showed no reluctance in designating one member of their team as a local "EndNote Champion". The only prerequisites were that these people should be enthusiastic about user education, have reasonably good technical skills and be willing to run at least one EndNote workshop per term. It was agreed that the provision of EndNote training would be an additional responsibility but it would not impinge on their existing priorities. 
In May 2004, a "training the trainers" session was run for the new EndNote Champions. Run by the Research Support Librarian and Serials Librarian, the programme included a standard three-hour EndNote training workshop. This was preceded by a presentation on the advantages to the Library of delivering EndNote training and followed by an informal discussion on what was expected of the Champions. In order to ensure standardisation throughout the University, the new trainers were asked to use the existing workshop template as the basis of their own workshops. The template included not just PowerPoint slides but a complete script that the Champions could quote verbatim or adapt as desired. They were encouraged to make workshops more relevant to their own subject areas by selecting appropriate databases when demonstrating the connection file, import filter and direct export functions. It was pointed out that the workshops offered a good opportunity to promote relevant but perhaps underutilised resources. For training aimed at the Faculty of Art and Design, an additional component on working with images was created. Trainers were also provided with a promotional flyer, a booking form, a feedback form and a workshop checklist (a practical list of steps relating to promotion, taking bookings, equipment issues, and providing postworkshop support to participants). All documentation relating to EndNote training was made available on the Library Intranet.

The new EndNote Champions were encouraged to call on the expertise of the Research Support Librarian and the Serials Librarian when running their first workshops. The more experienced trainers were able to take on the role of main presenter with the new trainer playing a supporting role until competence was developed and the new Champion felt confident enough to lead the workshops, again with the support of another Champion. Rehearsals were recommended as a way for the new Champions to become familiar with EndNote, the workshop script and the computer suites. 
In order to facilitate communication within the group, an e-mail discussion list was created. This has been used to share experiences, both good and bad, and to build a sense of camaraderie. It has also served as a way to communicate news of software developments, including additional connection files and import filters. A further means of facilitating the sense of collegiality was the organisation of a second workshop for EndNote Champions held in June 2005 (when it was agreed that this should become an annual event). Given the geographical spread of the University, many members of library staff rarely have the opportunity to meet other than via email and telephone conversations. The workshop allowed trainers to meet in person and informally discuss experiences and common problems. It also provided an opportunity to enhance the trainers' skills: the Research Support Librarian provided a demonstration of the basics of editing output styles and developers of the new online tutorial were able to offer their colleagues a preview.

Between June 2004 and July 2005, the library's EndNote Champions ran a total of 38 workshops. These were all targeted at academic staff and postgraduate students. On average, there were ten participants per workshop making the total number of participants more than tenfold that of the previous year. At the last count, the MMU Library has twenty EndNote Champions drawn from a cross-section of library staff ranging from senior managers with years of user education experience to junior members of staff full of enthusiasm and eager to develop new skills. There is at least one Champion from every subject team and every site, plus others from central services such as Library Support Services and the Electronic Services Development Team. As the team-teaching approach continues to be used for workshops, Champions are able to call on trainers from other teams for assistance and cross-site collaboration has become the norm.

\section{DEVELOPMENT OF ONLINE TUTORIALS}

Feedback from academic staff consistently included requests to extend EndNote training to undergraduate students. The academics pointed out the difficulties that 
they had not only in introducing the concept of citing references to undergraduates but also in providing details of how to do this correctly. EndNote training, they felt, would provide an easy solution to both problems. Students would learn of the need to cite references correctly in their academic work and would be introduced to a simple practical method for doing this. As citing references accurately can count for as much as $10 \%$ of an assignment's marks, undergraduate students would have a strong incentive for adopting EndNote.

With a full-time equivalent undergraduate population of just under 19,000 students, running hands-on workshops even with the increased number of trainers was simply not feasible. Online training was identified as the solution. Not only had research demonstrated the successful use of online tutorials for tackling students' referencing errors (Kendall, 2005) but the MMU Library already had considerable experience in the use of INFORMS online tutorial software to provide self-paced, web-based training in the use of databases and other electronic resources.

INFORMS is the outcome of a centrally-funded Joint Information Systems Committee (JISC) project led by the University of Huddersfield, University of Oxford and Loughborough University in the United Kingdom (Franklin and Stubbings, 2003). It provides an online tool that permits the easy creation of electronic tutorials for information skills training. INFORMS uses split screens with a step-by-step instructional guide, called the "Guide @ the Side", appearing on the left-hand side of the screen, and live access to the electronic resource on the right-hand side of the screen. This split-screen format permits users to read information and tips about how to use the resource, while working through guided searches on the live resource itself. The process of creating and formatting an INFORMS tutorial is extremely easy, as content can be written on a series of online forms using basic mark-up language, which is then automatically converted into the online guide. 
The use of INFORMS to teach EndNote skills was something of an innovation as INFORMS was designed for use with web-based resources. There were concerns that, since EndNote is not web-based but sits on the hard drive of the individual PC, the two might not be compatible. As it turned out, the only problem was that it was not possible for INFORMS to launch EndNote automatically on the right-hand side of the split screen. Library staff found a practical solution to this problem: the initial screen of the EndNote tutorial provides detailed instructions for users on how to open EndNote, and then how to resize it so that the "Guide @ the Side" remains visible.

A further innovation was the inclusion of images which, to the best of our knowledge, had not been used in INFORMS tutorials before. One of the developers of MMU's EndNote tutorial discovered that the use of more advanced HTML tags (rather than the basic mark-up language normally used with INFORMS) would allow for the inclusion of images. As a result, images of EndNote's toolbar icons, as well as various buttons from the databases used for practising direct export, were inserted. Not only do they make the tutorial more visually appealing by breaking up the text with colorful graphics, but they also aid navigation and reduce the need for clumsy instructions such as "Click on the red button with the white $\mathrm{X}$ on the right-hand side of the top of the screen".

The draft version of the tutorial was developed by three EndNote Champions over a period of six weeks. It was beta-tested in April 2005 by paraprofessional members of staff with no previous EndNote experience, and by academic staff and students of the University's Department of Information and Communication. Feedback was enthusiastic. Seen as particularly positive were the ease of navigation, the clarity of the instructions, the constant presence of a table of contents "so if you need to refer back to something you don't have to flick through all the pages", and the availability of step-by-step instructions on the same screen as EndNote. Inevitably, feedback also suggested some improvements and highlighted some negative 
aspects of the tutorial. In particular, the process of opening and resizing the EndNote window to produce the split-screen approach was considered cumbersome and confusing by some users. One user pointed out her frustration that she "had to write down the instructions before being able to open the programme correctly". Unfortunately, this remains unavoidable as long as our access to EndNote is not web-based, but it is hoped that handouts providing step-by-step instructions may alleviate some of the difficulties.

Where possible, improvements based on the feedback were incorporated into the final version of the tutorial which was launched in June 2005. The tutorial has been kept to a manageable length of 45 minutes and includes:

- Three methods of input: manual; connection files; direct export

- Information about output styles

- Cite While You Write.

Owing to their complexity, import filters were not included in this introductory tutorial. It was felt that most undergraduate needs would be met by the other three input methods.

The tutorial offers an introduction to the software, instructions on how to use various key features, and practical exercises. It consists of a series of fifteen steps that users can work through at their own pace. Although designed to be followed in a linear fashion, users can jump ahead to whichever sections they feel are most relevant, or return to steps they want to repeat by using the interactive table of contents. Likewise, although designed to be used on-campus, as the tutorial is available online it can be used by any off-campus users who have access to both EndNote and the Internet.

The tutorial can be used in a number of ways. It can be worked through by individuals on their own or it can form the basis of a workshop led by either library 
staff or members of academic staff with only basic levels of EndNote expertise. The tutorial has already been incorporated into the Research Methods unit of the MA in Library and Information Management and will be promoted in student handbooks produced by the Faculty of Art and Design. Because INFORMS and all tutorials created using it are essentially "shareware", MMU's EndNote tutorial is now available to other United Kingdom Higher and Further Education libraries which are free to copy and customise it for their own training purposes (Manchester Metropolitan University Library, 2005a).

A second INFORMS tutorial on editing output styles was launched in early Sepember 2005. Despite the availability of more than 1000 EndNote output styles, it is rare to find a style that matches a user's exact requirements. Editing output styles is a simple process but there had been what appeared to be an insurmountable barrier to the provision of training in this area. Editing requires access to the EndNote programme on a PC's hard drive but, for understandable security reasons, such access is not permitted within the University's computer suites. Library-led workshops were, therefore, simply not possible. Thanks to the INFORMS online tutorial, anyone with access to the hard drive (eg, all members of academic staff, plus staff and students with a personal copy of EndNote on their home PC or laptop) can now teach themselves how to edit output styles (Manchester Metropolitan University Library, 2005b).

\section{BENEFITS OF ENDNOTE TRAINING}

The benefits to academics and students of the Library's EndNote training programme are clear and include:

- Improved management of references and the use of those references within citations and lists of references. 
- Increased confidence when undertaking academic work. One student reported "feeling less daunted about doing my dissertation" after attending an EndNote workshop.

- Increased familiarity with the electronic resources provided by the Library. During the course of a workshop, participants are given hands-on experience in using relevant electronic resources with which they are often not familiar. One participant stated that a positive outcome of the course had been that she had learned "how to use library databases more effectively".

- Awareness of other training courses provided by the Library. A common question from workshop participants is "Do you run any other training courses? l'd like to know more about this database".

- Skills and resources (the INFORMS-based EndNote tutorials) for academic staff to use to incorporate EndNote training into the curriculum. One of the participants stated that she now felt "more confident to teach it to other people".

Less expected were the benefits that have accrued to the Library and the individual EndNote Champions from taking on the task of EndNote training and support initially and erroneously seen by some as an unwanted burden. The benefits include:

- Enhancement of the Library's profile within the University. The Library is recognised and appreciated as the provider of a service that academics have identified as crucial to themselves and to their students, both postgraduate and undergraduate.

- Acknowledgement of the educational role played by library staff. During an EndNote workshop, academic staff become students, and librarians, not always recognised for their pedagogical skills, become the teachers. 
Feedback consistently has included positive comments such as "good clear communication and support" and "You should have been a teacher".

- Provision of a venue for informal but effective communication between library staff and academic staff. The workshop format, in particular, helps to break down barriers and allows both participants and trainers to get to know one another better. From the point of view of library staff, this may be because the academics enter into a space in which library staff feel more relaxed, rather than having library staff enter into intimidating spaces such as programme committees and faculty boards.

- Increased opportunities for the promotion of electronic services and training programmes provided by the Library.

- A chance for members of library staff not traditionally involved in user education to develop new skills and gain valuable experience.

- Mentoring opportunities, with experienced trainers working with junior members of staff to help develop their user education skills and confidence levels.

- Experience of alternative training methods; for example, the team-teaching approach and the workshop format. The Research Support Librarian observed that "I was afraid of running workshops as, unlike giving a formal presentation, I might lose control and couldn't predict what would happen. Now that I've developed some coping strategies, I get a real buzz from the excitement the workshop situation generates."

- Opportunities for library staff to develop new technical skills and experience, for example, INFORMS and, of course, EndNote itself.

- Cross-site collaboration and improved communication within the Library.

\section{CONCLUSIONS}

In recent postings to his weblog, Lorcan Dempsey urged libraries 'to 'fit in' with the working practices of their users" (Dempsey, 17 July 2005) and identified "the 
lightweight bibliographic apparatus of reading lists and citation managers [as] an important site of integration" (Dempsey, 5 March 2005). The MMU Library believes that the provision of EndNote training to academic staff and students has provided just such a "site of integration". It has offered library staff the rare opportunity to engage with users within the natural flow of their working practices and, in so doing, to meet a need that users themselves have identified as key to their academic success. By using this opportunity to its fullest, the Library has been able to meet users' additional, if initially unperceived, information needs and has profited in a number of unexpected ways.

\section{REFERENCES}

DEMPSEY, L., 17 July 2005. Lorcan Dempsey's Weblog on Libraries, Services and Networks: serving network people. Online. Available:

http://orweblog.oclc.org/archives/000714.html (Last accessed: September 23, 2005).

DEMPSEY, L., 5 March 2005. Lorcan Dempsey's Weblog on Libraries, Services and Networks: sharing metadata. Online. Available:

http://orweblog.oclc.org/archives/000603.html (Last accessed: September 23, 2005).

EAST, J.W, 2001. Academic libraries and the provision of support for users of personal bibliographic software: a survey of Australian experience with Endnote. LASIE 32: 64-70.

FRANKLIN, G. and R. STUBBINGS, 2003. A Critical analysis of the INFORMS Project at Loughborough University. . Online. Available:

http://informs.hud.ac.uk/informs/files/elitpaper.pdf (Last accessed: September 22, 2005).

KENDALL, M., 2005. Tackling student referencing errors through an online tutorial. Aslib Proceedings: New Information Perspectives 57: 131-145.

KOSKINEN, S., 2001. From Colonel Mustard to Rube Goldberg: teaching patrons how to manage bibliographies with EndNote. Art Documentation 20: 50-51.

MANCHESTER METROPOLITAN UNIVERSITY LIBRARY, 2005a. EndNote 8 tutorial. Online. Available: http://inhale.hud.ac.uk/perl/jump.pl?28-1608 (Last accessed: September 23, 2005).

MANCHESTER METROPOLITAN UNIVERSITY LIBRARY, 2005b. Advanced EndNote 8 tutorial: how to edit output styles.. Online. Available at: http://inhale.hud.ac.uk/perl/jump.pl?28-1816 (Last accessed: September 23, 2005). 
OWEN, D.J., 1997. Using personal reprint management software to teach information management skills for the electronic library. Medical Reference Services Quarterly 16: 29-41.

ROBINSON LEVY, S. and P.G. HINEGARDNER (1992). Teaching Pro-Cite: classroom instruction and consultations. Medical Reference Services Quarterly 11: 31-38.

SIEGLER, S. and SIMBOLI, B. (2002). EndNote at Lehigh. Issues in Science and Technology Librarianship 32. Online. Available: http://www.istl.org/02spring/index.html

(Last accessed: September 22, 2005). 